\title{
Face-to-face teaching changed too! Perspectives on the transition from large to small group teaching and learning from graduate teaching assistants
}

\author{
Daniel Tinnion \\ Edge Hill University \\ Thomas Simpson \\ Edge Hill University \\ Mitchell Finlay \\ Edge Hill University
}

Keywords: reflection; reflective practice; Covid-19; small-group; teaching; learning; higher-education.

\section{The challenge}

The Covid-19 pandemic presented many challenges to teaching and learning. One challenge that has received particular attention is the move from face-to-face teaching to an online approach, particularly how technology may have impacted such a transition (Carrillo and Flores, 2020, Crawford et al., 2020). However, the subtle challenges which arose for any face-to-face teaching that continued have received less attention. For example, government restrictions meant smaller student groups in the face-to-face classroom, which in turn required extensive changes to standard approaches to teaching. As Graduate Teaching Assistants (GTAs) on an applied, science-based course, the problem presented was how to plan and deliver highly interpersonal and interactive laboratory-based sessions to the small groups $(\leq 10)$ whilst constrained by Covid-19 restrictions.

Where teaching in larger groups is often viewed as more teacher-centred, teaching smaller groups is predominantly learner-centred and keeps the student in an active mode (Saiyad et al., 2018). Pre-Covid, the teaching duties of GTAs were mostly characterised by large group sessions in which the key challenge was how to convey information to many individuals simultaneously, with relatively little consideration given to addressing everyone 
separately. During the pandemic, the challenge instead became how to promote the interactivity that is inherent in small group teaching (Saiyad et al., 2018). This would require that we devote more time to engaging with students individually than is typical in large-group teaching (Walton, 1997). Covid-19 also necessitated many new safety considerations and, as such, the number of tools available to deliver in this manner was reduced. However, before participating in this process, we all agreed that the opportunity to better engage with students was at the very least valuable in terms of providing both parties with some increasingly rare social interaction and offering us, as GTAs, the opportunity to focus on teaching in a less familiar context. In short, the problem was: how do we facilitate engaging small group sessions whilst also considering any limitations due to Covid-19 safety measures?

\section{The response}

As GTAs facing the same general challenges and with the same students, albeit within the context of our own sub-discipline, we agreed that it was beneficial to collaborate to produce a framework for engaging our students in small groups once this scenario was better understood. Jones (2007) defines small group learning as a group of learners displaying three characteristics: active participation, a specific task, and reflection. Although participation is unlikely to be equal across all students, successful small group learning requires all members to engage and participate. Pre Covid-19, typical laboratory sessions could be said to adhere to these characteristics well, asking that students adopt roles in even smaller groups to guide one of their peers through an exercise performance test, often directly linked to the lecture material in some way. Unfortunately, Covid-19 measures reduced laboratory sessions to practical demonstrations with a single student. This could have created several problems that directly oppose effective small group teaching (Jaques, 2003). Using the following structure, we tried to encourage engagement and keep many of the qualities of a typical laboratory session:

\section{Brief introduction to the laboratory material and demonstration of task}

Summarise the key concepts to provide foundations towards a greater understanding and establish a specific task (see: Jones, 2007). This is seen as the only portion that could be somewhat teacher-centred. 


\section{Questionnaire using Kahoot!}

Students use interactive software to answer a range of multiple-choice questions and receive a score based on speed and accuracy. This step aids in identifying which students may/may not require more assistance. Additionally, quieter students can also engage at their own level whilst more confident individuals can still thrive, that is, through friendly competition. This replaces observations that cannot be made without the flexible movement of the group.

\section{Teacher-led demonstration}

Teacher uses a student to demonstrate a particular test, for example, performing an ECG. To structure discussion alongside teacher 'points', Kahoot! questions are periodically introduced to maintain active involvement and guide the relative attention we may choose to give a particular aspect. What needs work? What is well understood?

\section{Using a 'spot-the-difference' type game}

Following the demonstration, the teacher uses a pre-recorded video or a set of true or false statements as examples to test students (in smaller groups) on how well they understood and retained what they observed. Students first discuss in small groups and then the outcome is discussed as a collective, allowing students to aid each other with minimal input. For the teacher this stage is the opportunity to tidy up everyone's understanding and bring the group to a good overall level. Success in this regard should naturally allow students to reflect on the learning that has occurred and/or may need to occur.

\section{Recommendations}

This is an example of how we responded to a very specific issue that arose during the Covid-19 pandemic and provides a highly practical process that may be used to overcome similar issues. Whilst the framework itself has great utility, it is the less obvious lessons that have been learned at this unique time that hold the most value.

Broadly, we were able to see that, amongst all the bells and whistles, teaching and learning can always be condensed into a handful of simple ideas (Race, 2003); an idea that has held true during the pandemic. Perhaps more novel in this article though, is the Journal of Learning Development in Higher Education, Issue 22: Compendium ～October $2021 \quad 3$ 
value of collaborating with similarly (in)experienced teachers to confront an obstacle to quality teaching.

Theoretically, collaborating on a project such as a lesson can allow the exchange of teaching ideas and experiences, discussion of teaching practices, the ability to provide each other with feedback and participate in further changes to teachers' cognition and/or behaviour (Meirink et al., 2007). In our group, one individual drew on a previous experience to suggest the use of Kahoot! to engage the entire group without lecturing them and where the ability to reorganise students into smaller groups, aiming to promote more individual-level discussion is unavailable, given Covid-19 restrictions. Following the first use of the framework, discussion arose around how else we may motivate the rest of the group to remain active, and so another member of the group proposed that Kahoot! could also be used flexibly after trying it themselves. Furthermore, some members of the group found that 'spot-the-difference' with a video was too easy for certain sessions and a deeper dive into the students' understanding was needed. In response, we agreed that in certain cases, true or false statements could be used instead or simultaneously.

Condensed into a single recommendation we would ultimately advise that all teachers, especially those of a similar experience level, make greater use of collaboration. In this example, we were able to arrive at very simple solutions to the problems presented, irrespective of the complexity of Covid-19, simply by having the desire to do well and the willingness to allow others to help us do so.

\section{References}

Carrillo, C. and Flores M.A. (2020) 'COVID-19 and teacher education: a literature review of online teaching and learning practices', European Journal of Teacher Education, 43(4), pp. 466-487. Available at: https://doi.org/10.1080/02619768.2020.1821184 (Accessed: 9 August 2021).

Crawford, J., Butler-Henderson, K., Rudolph, J., Malkawi, B., Glowatz, M., Burton, R., Magni, P. and Lam, S. (2020) 'COVID-19: 20 countries' higher education intraperiod digital pedagogy responses', Journal of Applied Learning \& Teaching, 3(1), 
pp.1-20. Available at: https://doi.org/10.37074/jalt.2020.3.1.7 (Accessed: 9 August 2021).

Jaques, D. (2003) 'Teaching small groups' BMJ, 326(7387), pp.492-494. Available at: https://doi.org/10.1136/bmj.326.7387.492 (Accessed: 9 August 2021).

Jones, R.W. (2007) 'Learning and teaching in small groups: characteristics, benefits, problems and approaches', Anaesthesia and intensive care, 35(4), pp.587-592. Available at: https://doi.org/10.1177\%2F0310057X0703500420 (Accessed: 9 August 2021).

Meirink, J.A., Meijer, P.C. and Verloop, N. (2007). 'A closer look at teachers' individual learning in collaborative settings', Teachers and Teaching: theory and practice, 13(2), pp.145-164. Available at:

https://doi.org/10.1080/13540600601152496 (Accessed: 9 August 2021).

Race, P. (2003) 'Learning in small groups', The Higher Education Academy. Available at: https://www.heacademy.ac.uk/system/files/resources/id475 learning in small grou ps Race.pdf (Accessed: 9 August 2021).

Saiyad, S., Mishra, S.K., Rimal, H., George, C. and Kaur, G. (2018) 'Teaching and learning through large and small groups', Journal of Research in Medical Education \& Ethics, 8(1), pp. 24-29. Available at: https://doi.org/10.5958/22316728.2018.00048.3 (Accessed: 9 August 2021).

Walton, H. (1997) 'Small group methods in medical teaching', Medical education, 31(6), pp.459-464. Available at: https://doi.org/10.1046/j.1365-2923.1997.00703.x (Accessed: 9 August 2021).

\section{Author details}

Daniel Tinnion is a PhD researcher and Graduate Teaching Assistant in Sport and Exercise Science (Physiology and Nutrition) at Edge Hill University. 
Thomas Simpson is a PhD researcher and Graduate Teaching Assistant in Sport and Exercise Science (Psychology) at Edge Hill University.

Mitchell Finlay is a PhD researcher and Graduate Teaching Assistant in Sport and Exercise Science (Biomechanics) at Edge Hill University. 